\title{
Exploración de las experiencias memorables y la fidelización en las ventas por catálogo*
}

\author{
Simón Tamayo Buitrago ** \\ María Claudia Mejía-Gil ${ }^{\star \star *}$ \\ Lina María Ceballos ${ }^{\star * *}$
}

Fecha de recibido: 9 de diciembre de 2019 Fecha de aprobado: 19 de septiembre de 2020

\begin{abstract}
Para citar este artículo: Tamayo Buitrago, S., Mejía-Gil, M. C., \& Ceballos, L. M. (2021). Exploración de las experiencias memorables y la fidelización en las ventas por catálogo Revista Universidad E Empresa, 23(40), 1-34. https://doi.org/10.12804/revistas.urosario. edu.co/empresa/a. 8548
\end{abstract}

\section{Resumen}

A pesar de la importancia del canal comercial de venta directa en países latinoamericanos, como Colombia, pocas investigaciones abordan el tema. Con el fin de aportar al entendimiento de este canal, esta investigación

* Este artículo está basado en el trabajo de grado entregado por el primer autor para obtener el título de la Maestría en Mercadeo en la Universidad EAFIT (Colombia).

** Administrador de Negocios, especialista en Mercadeo y magíster en Mercadeo, títulos obtenidos en la Universidad EAFIT de Medellín (Colombia). Actualmente, es profesor de cátedra de Mercadeo en la Facultad de Ciencias Económicas y Administrativas de la Universidad de Medellín (Colombia). Correo electrónico: stamayo@eafit.edu.co

*** Ingeniera de Producción de la Universidad EAfIT (Colombia) y especialista en Gerencia de Mercados Globales de la Escuela de Ingeniería de Antioquia (Colombia). Con Maestría en Antropología Social y PhD en Ciencias Sociales de la Universidad de Antioquia. Actualmente es profesora asistente del Departamento de Mercadeo de la Universidad EAFIT. Investigadora del grupo Recursos Estratégicos, Región y Dinámicas Socioambientales (Rerdsa) de la Universidad de Antioquia y del Grupo de Estudios en Mercadeo (GEM) de la Universidad EAFIT. Correo electrónico: mmejiagi@eafit.edu.co. ORCID: https://orcid.org/0000-0003-4162-6635

**** Ingeniera de Producción de la Universidad EAFIT (Colombia) con MBA de la University of Wales, Institute Cardiff (Reino Unido) y PhD en Consumer, Apparel and Retail Studies de la University in North Carolina in Greensboro (Estados Unidos). Actualmente es profesora titular del Departamento de Mercadeo de la Universidad EAFIT. Investigadora del Grupo de Estudios en Mercadeo (GEM) de la Universidad EAFIT. Correo electrónico: Iceball4@eafit.edu.co. ORCID: https://orcid.org/0000-0001-5024-2591 
tuvo como objetivo explorar las experiencias memorables de las vendedoras por catálogo y su importancia en la fidelización con sus empresas gestoras. Este estudio de enfoque etnográfico se concentra en doce vendedoras, mujeres de diferentes edades y residentes del Área Metropolitana de la ciudad de Medellín, de los niveles socioeconómicos medio y mediobajo, por ser las variables demográficas más usuales de las vendedoras de venta directa en este contexto. Por medio de entrevistas a profundidad y observación participante, se encontraron dos perfiles de vendedoras: Jóvenes Independientes y Mamás Entusiastas, según diferentes variables como intereses personales, motivaciones e inhibidores. En los perfiles se identificaron también los factores y experiencias memorables que se relacionan con la fidelidad con las ventas por catálogo. Esta investigación busca generar una reflexión para entender qué se debe tener en cuenta en las estrategias de fidelización dentro del canal de venta directa, partiendo de la comprensión de las motivaciones de las vendedoras para la búsqueda de su mayor beneficio.

Palabras clave: venta directa; fidelización; experiencias memorables; ventas; marketing de experiencias.

\title{
Exploring Memorable Experiences and Loyalty in Catalog Sales
}

\begin{abstract}
Despite the importance of direct selling as a retail channel in Latin American countries, such as Colombia, limited research addresses the topic. In order to contribute to the understanding of this channel, this research aims to explore the memorable experiences of direct selling consultants and their importance in strengthening loyalty with the promoter companies. This ethnographic study focuses on 12 female consultants from different age groups residing in the metropolitan area of Medellin. The sample was comprised of women from both medium and medium-low socioeconomic levels, as these are the most usual demographic variables of direct selling consultants in this context. By using in-depth interviews and participant observation, two consultant profiles were found in accordance with different variables such as personal interests, motivations, and inhibitors: Young \& Independent and Enthusiastic Moms. In these profiles, factors and memorable experiences related to loyalty with direct selling were also identified. This research promotes reflection to better understand the main elements that should be considered in the implementation of loyalty strategies of the direct selling channel, including the motivations driving the consultants' greatest benefit.
\end{abstract}

Keywords: Direct selling; loyalty; memorable experiences; sales; experience marketing.

\section{Exploração das experiências memoráveis e fidelização em vendas por catálogo}

\section{Resumo}

Apesar da importância do canal comercial de venda direta em países latino-americanos, como Colômbia, poucas investigações abordam o tema. Com o intuito de contribuir para o entendimento deste canal comercial, o presente estudo tem como objetivo explorar as memoráveis experiências de vendedoras por catálogo e sua importância na fidelização com sus empresas gestoras. Este estudo, de enfoque etnográfico se concentra em 12 vendedoras, mulheres de diferentes idades e residentes da área metropolitana da cidade de Medellín, de níveis socioeconômicos médio e médio-baixo, por serem as variáveis demográficas mais comuns dentre as vendedoras de venda direta neste contexto. Por meio de entrevista de profundidade e observação participativa se encontraram dois perfis de vendedoras: Jovens Independentes e Mães Entusiastas, conforme diferentes variáveis como interesses pessoais, motivações e inibidores. Nestes, se identificaram também os fatores e experiências memoráveis que se relacionam com a fidelidade nas vendas por catálogo. Esta investigação busca gerar uma reflexão para compreender o que deve ser levado em consideração na elaboração de estratégias de fidelização dentro do canal de venda direta, partindo da compreensão das motivações das vendedoras buscando seu maior beneficiamento.

Palavras-chave: venda direta; fidelização; experiências memoráveis; vendas; marketing de experiências. 


\section{Introducción}

La Asociación Colombiana de Venta Directa (Acovedi, 2019a) define la venta directa como un canal de comercio por medio del cual se busca dar una asesoría detallada para cerrar un negocio de compra-venta, que se conoce como un "negocio de gentes", porque se considera que es fácil ser parte de este. A nivel informal, este canal es llamado generalmente ventas por catálogo. Según la revista Portafolio (2019), la venta directa es uno de los negocios con mayor crecimiento en Colombia en los últimos años. Ello se debe a que por este canal se comercializan productos como bebidas, ropa, artículos de hogar, cuidado personal, fragancias, joyería, alimentos, accesorios, entre otros, los cuales se ven beneficiados por su participación en este canal, porque ha jalonado sus ventas por encima de otros canales. Hoy por hoy, son cada vez más los hogares colombianos que compran por venta directa.

Al contrario de otros canales, el ambiente de desigualdad y desempleo que se vive en el país (Semana, 2019) ha facilitado el crecimiento de la venta directa, porque este canal se convierte en una fuente fácil de ingresos para aquellas personas que buscan un sustento, pues los requisitos de entrada son mínimos y los beneficios son tangibles. En relación con esto, Acovedi (2019a) aclara que las empresas que trabajan con canales de venta directa obtienen una fuerza de ventas flexible sin un contrato laboral que las condicione. A pesar de las ventajas, la retención de los vendedores por parte de las empresas gestoras es un reto, debido a la alta competencia que existe relacionada con múltiples catálogos disponibles en el mercado (Bates, 2016), lo que ha generado que las vendedoras sean difíciles de satisfacer y estén constantemente buscando mejores condiciones en el mercado. Por lo anterior, es fundamental para las compañías que distribuyen por este canal, encontrar la manera de fidelizar a sus vendedores y así garantizar su viabilidad económica.

Se han realizado estudios en los que Colombia es un ejemplo de la latente internacionalización de los sistemas de mercadeo multinivel en los países de América Latina dirigidos a poblaciones de escasos recursos (González, 2016). Otros estudios se han centrado en las características que determinan el perfil de los vendedores de venta por catálogo y de cómo estos requieren estrategias de mercadeo diferenciadas (Posada et al., 2008), en las cuales se resaltan factores estimulantes para ingresar al negocio como los ingresos, el fortalecimiento de la identidad o la posibilidad de ampliar las conexiones con otras personas (Acovedi, 2015; 
Chu \& Segre, 2010). Sin embargo, no se han encontrado estudios disponibles enfocados en la fidelización de los vendedores, y menos, en regiones como Iberoamérica.

En países como Sudáfrica, que comparte con Colombia su contexto de alta desigualdad (Amnistía Internacional, 2018), se han estudiado las implicaciones sociales y el beneficio que existe en el empoderamiento de las mujeres a través de la venta por catálogo (Crittenden et al., 2018). Lograr dicho empoderamiento partiendo del impacto de las experiencias memorables que las empresas gestoras puedan tener con los implicados, se convierte en una oportunidad para ser competitivas. Este estudio pretende generar una reflexión al respecto. Por medio de la utilización de la etnografía como enfoque (Guber, 2001), esta investigación tuvo como propósito analizar cómo las experiencias memorables que viven las vendedoras por catálogo propician su fidelización. La metodología usada fue de tipo cualitativo y exploratorio. Los hallazgos de esta investigación podrían interesar a empresas gestoras de venta directa en el momento de desarrollar estrategias de fidelización. Este artículo aporta sugerencias sobre el proceso de interacción con las vendedoras y la comprensión de las motivaciones e inhibidores de ellas en este canal.

\section{Marco de referencia conceptual}

A continuación, se explican tres temáticas que posibilitan el entendimiento del presente estudio: venta directa, experiencias memorables y fidelización de vendedores.

\subsection{Venta directa}

Para entender mejor el contexto del objeto de investigación, es necesario conocer el panorama que representan las ventas por catálogo. Para Acovedi (2019a), las siguientes características distinguen la venta directa: se presenta por fuera de un local comercial, es usual que se dé en el domicilio del consumidor, requiere un contacto personal y no existe una relación contractual entre la empresa gestora y el vendedor. Adicionalmente, en la venta directa existe un alto servicio al cliente; es una fuente de ingresos sin restricción 
de sexo, edad, nivel educacional o experiencia previa; ofrece flexibilidad en el horario de venta, y las metas de crecimiento propias son de cada vendedor.

En Colombia, la venta directa tiene un gran potencial, porque ha crecido en los últimos años, según lo corrobora la Federación Mundial de Asociaciones de Venta Directa (wFDSA, 2018). En nuestro país se estima que más de dos millones de personas se dedican a la comercialización de productos por catálogo, con un aumento del $2 \%$ al $9 \%$ entre 2009 y 2015 (Gómez, 2015). Parte de su éxito radica en que es un canal que le permite a cualquier persona, sin mayores restricciones, cierta independencia económica. En un ambiente de alta desigualdad en Colombia (Jiménez, 2015), el desempleo es un factor común para todos los estratos, y este canal alternativo se ha convertido en una oportunidad para todo aquel que requiera un apoyo financiero. A pesar de las facilidades expuestas, la relación de las empresas gestoras con los vendedores que ingresan en el negocio no es sencilla y existe una competencia intensa (Bates, 2016).

Al respecto de la venta directa, Ongallo (2007) agrega que es una oportunidad, no exenta de riesgo, en la que el vendedor (ya sea un agente, promotor o distribuidor) ofrece su producto, con los instrumentos que la compañía le proporciona y con los recursos propios de su formación o experiencia comercial. Este autor argumenta que elementos como el producto, la comunicación, la motivación de los vendedores, el catálogo, la comisión, el precio, las habilidades y el marketing son factores de la venta directa que se conectan y enriquecen entre sí. Un ejemplo de ello es que la relación con los vendedores trasciende de un tema netamente económico, pues a pesar de no contar con un contrato laboral, quieren un reconocimiento por un trabajo bien hecho, relacionarse con otras personas, sentirse vinculadas a una organización, conocer oportunidades, entre otros. La venta directa hace parte del marketing directo que, según Alet (2007), se define como:

Un sistema interactivo de comunicación que utiliza uno o más medios, dirigido a creary explotar una relación directa entre una empresa y su público objetivo, ya sean clientes, clientes potenciales, canales de distribución y otras personas de interés, tratándoles como individuos y generando tanto respuestas medibles como transacciones en cualquier punto. (p. 29) 
Según esta definición, la venta directa se presenta como un sistema para profundizar en las relaciones con las personas, porque es una forma de interactuar en gran medida entre comprador y vendedor. Alet (2007) resalta que algunas de las ventajas del marketing directo son la posibilidad de tener un público objetivo preciso, crear clientes al mismo tiempo que se realiza la venta, medir de manera clara los resultados de cada acción y organizar y mantener una base de datos. El autor agrega que este marketing también facilita el control de la estrategia comercial, pues se pueden realizar tácticas o estrategias sigilosas, solo visibles por sus destinatarios.

Adicionalmente, Alet (2007) afirma que es importante entender el contexto que propicia la existencia del marketing directo: cambios en los clientes, desvalorización de gran cantidad de marcas, niveles de servicio muy bajos, saturación de medios de comunicación, aumento del poder del canal de distribución y nuevas tecnologías. Estos factores hacen que la venta directa tome fuerza y potencie la oportunidad de negocio que ofrece el canal de venta directa, en el cual se ha visto una transformación en la última década con políticas de inclusión social en Medellín, por ejemplo (Santoro, 2019).

Según lo presentado en esta subsección, se puede inferir que la fuerte competencia del canal, junto a un cliente informado, ha derivado en la necesidad por parte de las empresas gestoras de construir estrategias de fidelización que generen experiencias memorables con el fin de ser competitivos. De acuerdo con los anteriores factores, surge además la necesidad de entender cuáles son los momentos que fidelizan a las personas que trabajan en este medio, sus necesidades y motivaciones, para poder traducirlas en una oferta de valor que ajuste las metas organizacionales con las vidas de las personas que buscan mejores oportunidades laborales.

\subsection{Experiencias memorables}

Aparte de entender el contexto de la venta directa, es también importante acercarse al concepto de experiencia, que se refiere a la interpretación de una serie de encuentros e interacciones diseñados por un proveedor de servicios (Hume et al., 2006). En este caso, la presente investigación se enfoca en la experiencia de los vendedores, y no la del cliente final como tal. Por tanto, y basados en Hume et al. (2006), se definirá la experiencia de un vendedor de venta directa como la interpretación de una serie de encuentros e interacciones 
diseñados por la empresa gestora. Tal definición lleva a inferir que, para un vendedor, una vivencia puede ser agradable o, por el contrario, lamentable, lo que traerá consecuencias en el relacionamiento futuro que tenga con esa empresa gestora.

Por lo anterior, trabajar para que este vendedor experimente un conjunto de sensaciones o emociones memorables predeterminadas por medio de un servicio recibido es la esencia de la gestión de experiencias (González \& Poey, 2011). Para Segura y Garriga (2008), el marketing de experiencias se define como:

El proceso que incide específicamente en aportar un valor a los clientes, vinculado a las experiencias de estos con los productos y servicios que se les ofrecen, proporcionándoles una información-comunicación suficiente para ayudarles a tomar la decisión de compra actual y fidelizarlos en un futuro. (p. 268)

Segura y Garriga (2008) hacen hincapié en que, a través del gerenciamiento del proceso de la experiencia con el vendedor, las empresas pueden interactuar, transmitir y comunicar aspectos como sentimientos, emociones, marcas, valores y la historia de una organización. Según Cadavid (2004), las empresas tienen que involucrar el marketing de emociones y experiencias en sus estrategias comerciales, para fidelizar a los clientes mediante sensaciones memorables y atender el mercado de manera competitiva. Los bienes y servicios no son suficientes: las personas que viven un servicio están esperando experiencias únicas y personales, por lo que las empresas gestoras están obligadas a diseñar el servicio acordemente (Zomerdijk \& Voss, 2010). Por lo tanto, deben comprender las estrategias comerciales y la innovación en términos de diseño de experiencias emocionales vinculantes con su público de interés (Pine II \& Gilmore, 2014).

Una experiencia memorable se define como la evaluación subjetiva y personal en relación con el compromiso que tiene una persona con un evento, antes de vivirlo, durante este y después (Tung \& Ritchie, 2011). Pine II (2011) complementa lo anterior mencionando que una experiencia memorable no solo es sencilla, conveniente o sin complicaciones, sino que se caracteriza por hacer que los clientes quieran pasar su tiempo con la empresa que la ofrece. Generar una experiencia memorable comprende varios elementos. Para Lemon y Verhoef (2017), las experiencias deben suscitar respuestas cognitivas, emocionales, comportamentales, sensoriales y sociales por parte de las personas frente a una 
oferta de valor; por tanto, una respuesta positiva en dichos ámbitos es capaz de generar una experiencia memorable o, en caso contrario, una respuesta negativa, que acarrea una experiencia lamentable.

Dichas dimensiones pueden relacionarse con los principios desarrollados por Devine y Gilson (2010), para llevar a cabo una estrategia de experiencias memorables. Estos autores proponen cinco principios: a) superar las malas experiencias lo más pronto posible, b) identificar los momentos que generan inconformidad y disminuirla revisando los aspectos positivos que se puedan extraer de ellos, c) planificar los momentos finales con los clientes para generar un alto impacto, d) dar a los consumidores la oportunidad de elegir (particularmente si existe un proceso incómodo) y e) dar y mantener hábitos a los clientes. Los anteriores elementos derivan en una experiencia memorable y, con ella, la posibilidad de generar fidelización.

\subsection{Fidelización de vendedores}

Usualmente, la fidelización de un vendedor es la consecuencia de la suma de experiencias que el individuo tiene con un producto o servicio, y dichas experiencias pueden ser interacciones físicas o emocionales dentro de toda la cadena de valor de una organización (i.e., empresa gestora del catálogo) (Mascarenhas et al., 2006). La importancia del enfoque organizacional en estrategias de fidelización radica en que incrementar la retención del vendedor disminuye los costos de atracción y de marketing (Stan et al., 2013), pues conseguir un cliente nuevo es entre cinco y siete veces más caro que retener uno actual (Kotler \& Keller, 2006). Los esfuerzos de retención no solo hacen que el vendedor permanezca mayor tiempo con una compañía, sino que hable favorablemente de ella, preste menos atención a marcas competidoras y, especialmente, lo hace menos sensible a las ofertas y a los precios de estas (Aaker, 1991; Bowen \& Shoemaker, 1998; Homburg et al., 2005; Kotler \& Keller, 2012).

Los determinantes de la fidelidad de un cliente son complejos, dinámicos, cambiantes y evolucionan en el tiempo (Johnson et al., 2006). Estas definiciones y situaciones presentadas en cuanto a fidelización aplican no solo a clientes, sino también a los vendedores de venta directa, quienes posiblemente buscan los catálogos que ofrezcan mejores experiencias, entre ellas los que sean más fáciles de vender. Ayudados por las herramientas 
tecnológicas, los negocios que desarrollen la simplificación de los procesos y faciliten las conversaciones con sus clientes y entre estos lograrán entablar mejores relaciones y una mayor fidelización con ellos; el análisis de datos del negocio debe llevar a la generación de experiencias personalizadas y más enriquecedoras (Jones, s.f.).

La fidelización de vendedores es fundamental para los modelos de venta directa, pues el crecimiento en la continuidad de los pedidos permite darle estabilidad financiera a un negocio que se moviliza a través de créditos y una cartera en riesgo importante. De acuerdo con Acovedi (2015), el principal miedo de los vendedores por catálogo está relacionado con el incumplimiento de los clientes, que pueden llegar a afectar de forma negativa su historial crediticio, al generarles endeudamiento con las empresas gestoras.

\section{Aspectos metodológicos}

Con el fin de desarrollar los objetivos propuestos, se llevó a cabo una investigación exploratoria de carácter cualitativo. Mediante un enfoque etnográfico que incluía entrevistas a profundidad y observación participante, se conocieron a doce mujeres y se entendieron sus interacciones con las empresas gestoras de venta directa en el Área Metropolitana del Valle de Aburrá, que contiene la ciudad de Medellín. En coherencia con lo dicho por Guber (2001), este enfoque permitió mayor cercanía con las personas seleccionadas para conocer la situación de estudio de una manera amplia, puesto que es una de las formas más útiles para descubrir, examinar y reflexionar ampliamente sobre diferentes conceptos teóricos en situaciones concretas.

Para determinar los criterios de selección de las participantes se tuvieron en cuenta las cifras presentadas por Acovedi, Nielsen y la Gobernación de Antioquia. Según Acovedi (2015), el 89\% de las personas que se dedica a la venta directa son mujeres y el $85 \%$ de ellas vive en barrios de nivel socioeconómico 1, 2 y 3 (bajo y medio-bajo). Se aclara que el artículo 102 de la Ley 142 de 1994, del Gobierno de Colombia, indica que el país está estratificado del 1 al 6, siendo el estrato 6 el nivel socioeconómico más alto. De acuerdo con Nielsen (2014a), el mayor gasto en venta directa se hace en un $38 \%$ en los hogares 
de clase media y en un $30 \%$ en los hogares de estratos bajos. Por lo tanto, se reclutaron para esta investigación vendedoras en los estratos 2 (4 participantes) y 3 (8 participantes). Su ubicación en municipios del Área Metropolitana del Valle de Aburrá (Itagüí, Sabaneta y La Estrella) es coherente con lo anterior, pues un gran porcentaje de la población de dichos municipios pertenece al estrato 2 (29.7\%) y al estrato 3 (51.5\%), de acuerdo con las cifras presentadas por la Gobernación de Antioquia (2017), basadas en la Encuesta de Estratificación Socioeconómica de Viviendas.

Las participantes se seleccionaron a conveniencia y el criterio para elegirlas fue, además de las variables demográficas, un alto número de pedidos a una empresa de venta directa de la ciudad $^{1}$ y que realizaron durante el semestre inmediatamente anterior a la recolección de datos. Antes de la visita al hogar de cada vendedora elegida, se llamó telefónicamente para explicarle el encuentro investigativo y planificar una cita. Después de que firmaron el consentimiento informado, la visita tuvo una duración aproximada de una hora y media, en la cual se tomaron apuntes de lo observado dentro de la vivienda de la vendedora y fuera de esta. En el tiempo de la visita, se llevó a cabo una entrevista a profundidad con preguntas agrupadas en tres secciones. En la primera se plantearon preguntas acerca del contexto personal y familiar de la participante y de sus percepciones sobre el negocio de venta directa, con el objeto de determinar los motivadores e inhibidores para vender por catálogo. En la segunda sección se indagó de forma puntual por los momentos que derivaban en experiencias memorables en este negocio. En la tercera sección, las preguntas se enfocaron en describir los factores que influyen de manera positiva o negativa en la fidelización de la vendedora.

Las características demográficas de la muestra se pueden ver en la tabla 1. La edad promedio de las personas visitadas fue de 43 años: la menor tenía 21, y la mayor, 61 años. La media de hijos fue de uno por familia; 8 (67\%) de las participantes eran casadas, 9 (75\%) vivían con su pareja y, adicionalmente, los ingresos por ventas por catálogo no eran el principal sostén económico de su hogar para ninguna de las participantes. La muestra se clasificó en cuatro grupos de edad diferenciados, observando el entorno y entrevistando a varias personas por cada grupo. Se aclara que los nombres utilizados en este informe son seudónimos para preservar el anonimato de las participantes.

La empresa de venta directa involucrada en este estudio permanecerá confidencial para proteger el anonimato de las participantes. 
Tabla 1. Características demográficas de las participantes

\begin{tabular}{|c|c|c|c|c|c|c|}
\hline Participante & Edad & $\begin{array}{c}\text { Estado } \\
\text { civil }\end{array}$ & Hijos & Con quién vive & $\begin{array}{l}\text { Sostén } \\
\text { económico } \\
\text { del hogar }\end{array}$ & Estrato \\
\hline Participante 1 & 45 & Casada & Sí (2) & Esposo y dos hijas & Esposo & 3 \\
\hline Participante 2 & 50 & Casada & Sí (1) & Esposo e hija & Esposo & 3 \\
\hline Participante 3 & 52 & Casada & Sí (1) & Esposo e hija & Esposo & 3 \\
\hline Participante 4 & 61 & Separada & Sí (1) & Mamá (adulto mayor) & Ella & 3 \\
\hline Participante 5 & 45 & Separada & Sí (1) & Sobrina y mamá & Ella & 3 \\
\hline Participante 6 & 37 & Casada & Sí (2) & Esposo e hijos & Esposo & 3 \\
\hline Participante 7 & 29 & Casada & No $(0)$ & Esposo y hermana & Esposo & 3 \\
\hline Participante 8 & 21 & Soltera & No $(0)$ & Mamá, papá, hermana y prima & Papá & 3 \\
\hline Participante 9 & 54 & Casada & Sí (1) & Esposo e hijo & Esposo & 2 \\
\hline Participante 10 & 50 & Casada & Sí (2) & Esposo e hijas & Esposo & 2 \\
\hline Participante 11 & 33 & Casada & Sí (2) & Esposo e hijos & Ella & 2 \\
\hline Participante 12 & 33 & Unión libre & Sí (1) & Pareja e hijo & Esposo & 2 \\
\hline
\end{tabular}

Fuente: elaboración propia.

Durante la recolección de datos se logra la saturación teórica, al no obtener datos nuevos de las participantes (Corbin \& Strauss, 2002). Al finalizar las visitas, se analizó la información codificando en primera instancia una matriz de datos en Excel con las observaciones y respuestas de las personas y organizándola de forma separada de acuerdo con cada objetivo específico. En segunda instancia, se identificaron patrones en los datos que permitieron generar categorías de análisis de la información. En tercera instancia se obtuvieron inferencias y conclusiones al relacionar las categorías con los distintos hallazgos identificados en las entrevistas y la literatura. En suma, se realizó un ejercicio de categorización y análisis temático (Spiggle, 1994) que permitió simplificar, organizar, analizar e interpretar los datos.

\section{Presentación de resultados}

\subsection{Perfilación de las vendedoras por catálogo}

Con base en la interpretación de los datos, se identificaron dos perfiles de vendedoras, en los cuales la edad fue un factor importante de clasificación en el momento de estudiar 
sus motivaciones sobre el negocio de venta por catálogo. De acuerdo con esto, a continuación, se presentan estos perfiles: las mujeres de 20 a 45 años serán llamadas Jóvenes Independientes, y las mujeres de 45 años en adelante, Mamás Entusiastas.

\subsubsection{Jóvenes Independientes: "la venta por catálogo me permite manejar un negocio cuando quiero y como quiero"}

Natalia, la participante más representativa de este perfil, es una joven de 30 años que hace poco tiempo se casó y vive con Carlos, su esposo, y su hija Emiliana, quien se encuentra en su último año de guardería. Vive en un barrio de estrato 3 y el principal sostén económico del hogar es su esposo. Es una mujer con muchas metas personales; terminó sus estudios universitarios, quiere seguir creciendo profesionalmente y montar un negocio propio.

Su situación económica no es sencilla: tiene un trabajo formal en una empresa alejada de su casa y para mantenerlo debe renunciar a muchos momentos con su familia. De forma adicional, son escasos o nulos sus periodos de vacaciones, pues también debe hacer esfuerzos extra para ayudar con los gastos del hogar. Ella menciona que requería más dinero a medida que pasaba el tiempo en su época de estudio: "Yo empecé a buscar porque cuando estaba en la universidad siempre estaba apretada, yo necesitaba otra entrada más que me ayudara a conseguir mis cosas”. A pesar de esto, goza los momentos que tiene con sus seres queridos e intenta aprovechar al máximo los fines de semana con ellos, pues carece de tiempo libre.

Las cuestiones familiares son muy importantes para ella, pero el trabajo es algo vital en su vida y uno de los mayores logros que ha tenido. A Natalia le parece aspiracional ser parte de una empresa grande y reconocida; le preocupa quedar por algún motivo sin trabajo, pues tiene deudas pendientes por pagar. A Natalia le interesan los temas que permitan expresar su individualidad y mantenerse en contacto consigo misma. Ella cuenta que "la música, la fotografía, la moda... (y) la espiritualidad, me parecen interesantes, no soy muy religiosa pero lo espiritual, me llama mucho la atención”. Estos temas los comparte con su familia y amigos cercanos, quienes son personas en las que encuentra felicidad.

Ella no quiere más hijos y considera que ya es suficiente responsabilidad. Se ve en un futuro viajando en familia, estando con su niña. Ella aclara: "El año entrante tengo una 
meta con mi esposo y es irnos de paseo con la niña a conocer el mar. ( ¿Y adónde van a ir?) A Coveñas". Le tranquiliza encontrar bien a su familia cuando llega a casa y le angustia tener una necesidad o enfermedad y no tener cómo o con qué solucionarla.

Los días de Natalia son muy afanados; ella no tiene problema en tomar rutas de transporte con las que se pueda movilizar por la ciudad, porque están a una o dos cuadras de su vivienda. Sin embargo, a veces tarda en llegar a su destino. Su casa, por lo general, es tranquila; no se oyen casi los automóviles, pues no está ubicada en una calle principal, pero en algunas ocasiones se percibe ruido por parte de vecinos que escuchan música a un alto volumen. Alrededor de ella hay más casas, edificios, algunas tiendas con pequeños negocios, es un entorno que considera adecuado para entablar conversaciones en la calle. Ella está conforme con su hogar y no se queja; menciona que puede venderle fácil a quienes viven cerca, sin mantener demasiado involucramiento: "Yo siempre les muestro la revista, me compran, llevamos buena comunicación, les gustan los productos, es muy tranquilo. (¿Te gusta dónde vives?) Yo vivo muy feliz acá, es como muy apartadito”.

Ella no usa un automóvil, pero su esposo sí una moto para movilizarse. Actualmente, la guarda en las noches cerca de la sala, para que sea fácil en el momento de entrar o salir. Natalia en su sala tiene un sofá, una mesa central de cuatro puestos, televisor, equipo de sonido y computador de escritorio. Los electrodomésticos son modernos y en excelente estado; los cuida mucho. En el televisor ven novelas o películas en familia. Le gusta la tecnología: la ve como fuente de entretenimiento y el medio que posibilita las redes de contactos y de comunicación. Esto lo explica así:

La tecnología ahora es muy importante. Yo de redes sociales lo único que manejo es Facebook y WhatsApp, de lo otro no. A mi hija le presto la Tablet pero solo los fines de semana. La tecnología le sirve a uno pa todo, pa uno comunicarse con los seres que están en el exterior, saber de ellos, para consultas de ella.

Natalia ha encontrado en las empresas gestoras de venta por catálogo una oportunidad de negocio y una buena fuente de ingresos. Comenzó a vender los catálogos, porque "tenía necesidad, (antes) no trabajaba, mi niña estaba creciendo y yo estaba viendo que mi marido solo no era capaz con la obligación”. Además, encuentra en los catálogos un complemento a sus ingresos actuales, que puede gestionar en los momentos libres de 
su empleo. Por eso, es usual que en su casa no tenga a la vista de posibles visitantes los diferentes catálogos que maneja, pues los guarda en su bolso, listos para ser mostrados en su lugar de trabajo. Lo describe de la siguiente manera:

Fue algo... No sé si fue un llamado o algo que surgió. Yo nunca me lo hubiera imaginado, como vendiendo así productos de revista (catálogo), pero mira, me está yendo bien. Incluso me ha beneficiado mucho que el producto me llega a la oficina porque mis mayores compradores son de allá.

Las compras generales para su casa las complementa con compras a sus catálogos, por lo que así se convierte en autoconsumidora. También adquiere otras cosas que necesita en tiendas cercanas o en almacenes con formatos de gran descuento. Lo que más compra es mercado para la casa y productos de aseo. Sin embargo, lo que más le gusta es comprar ropa, y esta la puede encontrar fácilmente en las revistas de los catálogos. Natalia se encuentra contenta con la venta directa. La entretiene recibir periódicamente su caja de pedidos y se siente a gusto en un negocio que le brinda posibilidades y productos de calidad. Ella explica:

Yo siento con esta revista alegría y confianza, porque me pongo tan feliz cuando me llega el pedido... Y confianza porque yo sé que todo lo que vendo de esta revista es de buena calidad. Sé que es bueno lo que le voy a entregar a los clientes o lo que voy a pedir para mí.

\subsubsection{Mamás Entusiastas: "haber formado una familia es el mayor logro porque la soledad aterra"}

Gloria es la participante más representativa de este perfil. Ella es una mamá de 52 años de edad, casada, quien vive con su esposo Fernando y su hija Daniela de 20 años, que se encuentra realizando una carrera técnica en una universidad de la ciudad. Tiene un perro grande y bien alimentado al que llama Apolo; ella ama a su mascota. Se reparten los gastos del hogar en pareja y tienen una casa en un barrio de estrato 3 .

Gloria es ama de casa, no tiene un empleo formal, pero encuentra los ingresos que necesita para pagar sus gastos a través de la venta por catálogo, a la que considera una 
gran oportunidad en un mercado laboral difícil y afirma que "por mi edad ya no me daban trabajo en otra empresa”. Es alguien que da la vida por su hija; está haciendo todos los esfuerzos posibles para darle una educación con la que pueda salir adelante, pues la motiva su familia. Ella explica "A mí me da tranquilidad (darle) el mejor cuidado a la familia y (ver que) van bien. A mucho esfuerzo se logró (posibilitarle) el estudio y todo para que más adelante pueda defenderse, sostenerse y conseguir un empleo". Gloria espera verse en un futuro con salud, paz y unión familiar. Le angustian los escándalos en la casa por situaciones de alcohol o que haya alguna necesidad y no tener cómo ayudar económicamente.

Su casa tiene una fachada de colores planos pastel, está ubicada al lado de la calle y, por lo tanto, el ruido y la polución que estos generan pueden llegar a ser considerables en ciertas horas del día. Dentro de su vivienda, el uso de la sala es múltiple, pues en ella se atienden visitas, es el lugar para comer y un espacio de trabajo. Otro tema importante para ella es mantener a su familia alimentada y le satisface ver la cocina llena; compra donde sea más económico, ya sea en tiendas de formatos de grandes descuentos o en tiendas de barrio cercanas. En su sala se pueden ver los catálogos de distintas empresas gestoras y los enseña cada que tiene una oportunidad. También al fondo del cuarto mantiene una vitrina llena de productos sin vender, premios y regalos de las compañías con las que ha negociado. Menciona que es usual la venta o la rifa de esta mercancía "fiada" (a préstamo) a personas interesadas de su barrio y que de esta forma se sostiene. Ella comenta sobre este tipo de ventas por catálogos:

\begin{abstract}
Casi siempre son cambios que me devuelven y no tengo dónde hacerlos. De lo que me gano de otro catálogo, los pago. Me sostiene que los clientes vienen y me compran acá y me van abonando, semanal o quincenalmente. Mis vecinos saben que yo vendo cositas acá, por medio de ellos la otra gente se va dando cuenta y vienen. O me llaman: "Gloria ¿de casualidad no tienes tal loción en tu casa?", y yo "Sí", y ellos me contestan: "¿Y será que me la puedes dejar fiada que es para un regalito?", y yo les contesto "Sí, venga por ella". Entonces luego ellos vienen, se la llevan y me la van abonando cada ocho o cada quince días. Ellos vienen porque me conocen y saben que son productos de buena calidad, de marca propia.
\end{abstract}

Tiene mucho por hacer durante el día: además de las tareas del hogar, recorre el barrio con frecuencia visitando a sus familiares, vecinos y conocidos para ofrecerles productos 
y el modelo de negocio con el que obtiene premios por sus ventas y el reclutamiento de personas nuevas. Ella menciona:

\begin{abstract}
Estoy con Natura, Avon, Ipanu, Lebon, Yanbal. (¿Por qué tantos catálogos?) Te digo con una sencilla razón: yo me muevo dentro de todo en este barrio, en el Centro, en urbanizaciones, unidades cerradas, desde el estrato alto, hasta el estrato normal, entonces, para todas las necesidades hay que tener (productos), no soy confiada con los clientes, porque yo sé más o menos dónde tengo que llegar para que haya una respuesta positiva.
\end{abstract}

Sus múltiples actividades relacionadas con la venta directa hacen que no tenga casi tiempo para compartir en familia; pero cuando llegan los fines de semana, trata de disfrutarlos al máximo. Sus diligencias cotidianas las realiza a pie; ella no cuenta con carro o moto, y tampoco con un garaje en su casa para disponer eventualmente de alguno de estos medios. Sin embargo, no tiene problema en tomar el transporte público que le queda cercano a su hogar, así se queje un poco de la congestión. Cada vez se da cuenta de la importancia de la tecnología: ella la asocia con las comunicaciones a través de un teléfono inteligente, porque es consciente del espacio que le quita a su vida, pero al mismo tiempo, la hace útil para gestionar las ventas desde su hogar. Ella explica: "Es un mal necesario, porque ya sin ese bendito aparato uno no puede hacer nada, ya hasta los pedidos se hacen por WhatsApp, entonces por eso te digo que es un mal necesario".

Gloria se siente admirada por las empresas gestoras de venta directa y considera que son sobresalientes con las que trabaja. Esto lo explica así: "(son unos verracos (jerga urbana que quiere decir que ponen mucho empeño y valentía) porque quien inventó la venta por catálogo tiene que haber sido alguien muy inteligente; vio que a la gente no le quedaba tiempo de salir a comprar. Son empresas que toman riesgos”. La tabla 2 resume aspectos clave en los perfiles encontrados y que se explicarán con mayor detalle en las próximas subsecciones. 
Tabla 2. Comparación de los perfiles

\begin{tabular}{|c|c|c|}
\hline Perfil & Jóvenes Independientes & Mamás Entusiastas \\
\hline Número de participantes & 5 & 7 \\
\hline Edad & $20-45$ años & 45 en adelante \\
\hline Descripción general & $\begin{array}{l}\text { Una mezcla entre individualidad, poco } \\
\text { tiempo disponible y la preocupación } \\
\text { económica inmediata. }\end{array}$ & $\begin{array}{l}\text { La angustia futura por la tranquilidad familiar } \\
\text { y la soledad. }\end{array}$ \\
\hline Verbatim distintivo & "Mi espacio, mi tiempo y mi dinero". & $\begin{array}{l}\text { "Haber formado una familia es el mayor } \\
\text { logro, porque la soledad aterra". }\end{array}$ \\
\hline Intereses personales & $\begin{array}{l}\text { La independencia, sus sueños y realiza- } \\
\text { ción profesional. }\end{array}$ & $\begin{array}{l}\text { La tranquilidad de su familia y el futuro de los } \\
\text { hijos. }\end{array}$ \\
\hline Condición laboral & Tienen un empleo formal. & No tienen un empleo formal. \\
\hline Fuente de ingresos & $\begin{array}{l}\text { El catálogo es una fuente de dinero } \\
\text { secundaria. }\end{array}$ & El catálogo es su fuente de dinero primaria. \\
\hline \multirow{6}{*}{ Motivaciones } & $\begin{array}{l}\text { El catálogo es un complemento a los } \\
\text { ingresos actuales, y lo pueden gestionar } \\
\text { en sus momentos libres. }\end{array}$ & $\begin{array}{l}\text { El catálogo es una oportunidad de negocio en } \\
\text { un mercado laboral donde es difícil encontrar } \\
\text { empleo para personas de este rango de edad. } \\
\text { Socializar con otros. }\end{array}$ \\
\hline & Bienestar y tranquilidad familiar. & \\
\hline & Compartir en familia. & \\
\hline & $\begin{array}{l}\text { Son una opción cómoda y fácil para gene } \\
\text { po requerido para las ventas. }\end{array}$ & ar ingresos y que ofrece flexibilidad en el tiem- \\
\hline & $\begin{array}{l}\text { Ofertas y premios de campaña, exclusivid } \\
\text { entregas de producto a tiempo. }\end{array}$ & ad, calidad e innovación de los productos, \\
\hline & El autoconsumo. & \\
\hline \multirow[t]{2}{*}{ Inhibidores } & Cambios y devoluciones. & $\begin{array}{l}\text { Agotados en los pedidos. Incumplimiento en } \\
\text { la entrega. }\end{array}$ \\
\hline & Cobro a los clientes. & \\
\hline Experiencias memorables & $\begin{array}{l}\text { Encontrar premios y sorpresas en su caja } \\
\text { des en el catálogo, asegurar una venta, re }\end{array}$ & $\begin{array}{l}\text { e pedidos, reuniones de conferencia, noveda- } \\
\text { conocimientos. }\end{array}$ \\
\hline \multirow{3}{*}{ Fidelización } & $\begin{array}{l}\text { Autoconsumo, comodidad para el mon- } \\
\text { taje de pedidos. }\end{array}$ & Interacción con otras personas. \\
\hline & $\begin{array}{l}\text { Planes de premios acordes al esfuerzo } \\
\text { realizado. }\end{array}$ & $\begin{array}{l}\text { Relacionamiento constante con la empresa } \\
\text { gestora. }\end{array}$ \\
\hline & Cambios y devoluciones en casa. & Eficiencia operativa. \\
\hline
\end{tabular}

Fuente: elaboración propia.

\subsection{Motivadores para vender por catálogo}

\section{Se pudieron identificar aspectos relevantes que motivan la venta por catálogo, de los cuales el bienestar de la familia del participante es el punto central. Por lo tanto, los catálogos se perciben con una herramienta para lograr este bienestar. Así lo confirma una Mamá Entusiasta:}


Lo que más me tranquiliza: que mis hijos y mi familia estén bien. Bueno y lo que me angustia: de pronto no tener con qué sostener y ayudar con los impuestos de esta casa... Me gusta mucho vender productos por catálogo porque eso me ayuda con la situación económica. (Participante 3, entrevista personal, 52 años, estrato 3)

A pesar del poco tiempo que pueden compartir juntos, la familia es el núcleo de sus vidas y trabajan por ella. Fue común evidenciar que la mayoría de participantes tienen poco tiempo libre. Al respecto, la participante 7 menciona:

Con el corto tiempo que le queda a uno (solo) saco espacio con mi esposo, porque mi hermanita trabaja, también estudia y casi no nos queda tiempo para compartir; pero con mi esposo sí saco los fines de semana un espacio para ir a cine o salir a comer helado. (Joven Independiente, entrevista personal, 29 años, estrato 3)

Este elemento convierte la venta por catálogo en una actividad lucrativa y atractiva, porque les brinda flexibilidad en el manejo de su tiempo y las personas pueden decidir cuál es el grado de involucramiento que quieren tener con una empresa sin perjudicar sus momentos especiales en familia. También fue usual escuchar que son muy pocos los periodos de vacaciones o que estos son inexistentes. La participante 6 afirma que "vacaciones en sí, no manejamos como mucho, si resulta un paseo a una finca pues armamos parche y nos vamos. O hacemos también paseos de olla" (Joven Independiente, entrevista personal, 37 años, estrato 3). Los viajes se convierten en un evento aspiracional y es algo que las empresas gestoras de venta directa ofrecen como premio a sus mejores vendedoras.

Se pueden identificar diferencias y similitudes en las motivaciones para vender por catálogo de las Jóvenes Independientes y las Mamás Entusiastas. Es claro que para las primeras, la independencia, los sueños personales y la realización profesional son importantes; mientras que para las segundas, la tranquilidad de la familia y de los hijos es su mayor prioridad. Una Joven Independiente expresa:

(Mi mayor logro fue) haber terminado de estudiar. Yo siempre había querido terminar mi carrera, pero por la llegada de Samu (su hijo), no pude, ahí se quedaron pendientes muchas cosas. Cuando él tenía dos o tres años, yo empecé a estudiar (otra vez); me 
metí por el lado de la moda y lo terminé, con las uñas, pero lo terminé. (Participante 12, entrevista personal, 33 años, estrato 2)

A su vez, una Mamá Entusiasta afirma:

Mi mayor logro personal es tener estas niñas (hija y sobrina) en el avance educativo en el que están, ya están a punto de graduarse, cada una va a sacar su carrera, y para mí, que quedé como papá y mamá, yo me siento un pavito real porque no cualquiera lo hace, y no es fácil, porque cuando llegan facturas, que hay que mercar, que la casa, mil cosas, y uno solito, entonces es muy fuerte. Ese es mi mayor logro y (también) mantenerlas unidas. (Participante 5, entrevista personal, 45 años, estrato 3)

Dichas motivaciones se ajustan a los modelos de negocio de venta por catálogo y en ellos encuentran posibilidades de alcanzarlos, porque la gestión de ventas se realiza de forma individual, ofrece opciones de crecimiento a través de planes de segmentación, cuenta con eventos de reconocimiento para las mejores vendedoras y existen premios de diversos tipos, muchos de ellos enfocados en satisfacer grupos familiares (por ejemplo, entradas a cine, boletos para parques o tardes de picnic).

Otro motivador es la facilidad con que se puede administrar el negocio a través de herramientas tecnológicas. Las Jóvenes Independientes perciben la tecnología (redes sociales y WhatsApp) como fuente de utilidad transaccional, de entretenimiento y de comunicación. Aunque las Mamás Entusiastas son más reacias a lo tecnológico que las jóvenes, estas asocian la tecnología con los celulares y las comunicaciones, siendo conscientes del tiempo que les quita a sus vidas. Sin embargo, para ambos grupos se convierte en un motivador, porque es fácil mantener un negocio a través de un teléfono inteligente que permita mostrar un catálogo virtual, sin la necesidad de salir de sus casas. Al respecto, una Joven Independiente afirma:

El celular y el computador, le facilitan a uno todo. Yo prefiero pagar las cosas (por estos medios), que tener que ir a hacer fila. Con los pedidos es superbueno (hacerlos) por WhatsApp. La tecnología es superbuena para el hogar, le sirve hasta para cocinar. Si usted no sabe, puede buscar una receta. Uno también busca para muchas cosas de aseo. (Joven Independiente, entrevista personal, 21 años, estrato 3) 
También coincide con ella una Mamá Entusiasta al hablar de las bondades de un teléfono inteligente: "(a la tecnología le veo uso) haciendo el pedido del catálogo, que lo hago por la página y (además) muchas cosas que uno encuentra por internet me gustan. Aunque casi no cojo el celular, si necesito algo lo busco" (Mamá Entusiasta, entrevista personal, 50 años, estrato 3).

Además de acceder a un sustento monetario a través de la venta por catálogo, la posibilidad de realizar esta actividad desde el hogar deriva en tener más tiempo con los seres queridos y estar más pendiente de los hijos. En coherencia con lo anterior, fue común encontrar en sus respuestas que les tranquiliza ver a sus familias en paz y con salud, y que les genera angustia no tener con qué pagar las cuentas de la casa o estar en un momento de necesidad económica. La participante 4 lo afirma:

Mi economía es lo que más me angustia, es la preocupación más grande porque es lo único que me falta. Y lo que me tranquiliza: que mi hijo esté bien, que tenga un buen hogar y que yo pueda cuidar a mi mamá. Eso es bueno, porque hay momentos difíciles, pero tener a mi mamá todavía en la edad que tiene y estar con ella, poderle servir me tranquiliza. (Mamá Entusiasta, entrevista personal, 61 años, estrato 3)

En este contexto, las participantes descubren que el negocio de la venta por catálogo y la facilidad de gestión que tienen coinciden con la tranquilidad que están buscando. En primer lugar, las Jóvenes Independientes encuentran que es un complemento o ingreso extra a sus salarios y que pueden manejarlo en los momentos libres de sus empleos formales. Mientras que las Mamás Entusiastas venden catálogos porque son una opción de negocio en un mercado laboral que difícilmente les da la oportunidad de trabajar de manera formal. El catálogo es su fuente de ingresos, como lo dice la participante 4: "porque no tengo otra forma, porque es lo más fácil que me queda a mí, por estar aquí en mi casa” (Mamá Entusiasta, entrevista personal, 61 años, estrato 3). Esto va en coherencia con sus intereses personales para evitar un momento de necesidad económica en su familia.

En segundo lugar, estas compañías ofrecen comodidad para generar ventas, porque no solo sus pedidos les llegan a sus casas, son a crédito y no tienen que hacer filas para comprarlos, sino que lo pueden vender a familiares, vecinos y conocidos. Fue común encontrar que las participantes venden varios catálogos, por la diversidad de necesidades 
que manejan estos clientes. Así aseguran una venta para cierto producto específico y van completando los montos mínimos exigidos para montar pedido en distintas empresas. La familia es el principal aliado y su mayor cliente, que se convierte fácilmente en una venta fija periódica.

También fue posible conocer que ambos grupos coinciden en ser autoconsumidoras de sus catálogos. Se motivan a comprar los productos porque les gusta para uso personal, les sirven en sus casas y suman en el valor de la venta acumulada exigida para llegar a los premios vigentes de cada campaña. No obstante, uno de los inhibidores para comprarlos es el precio; ellas deciden adquirir los productos que sean más económicos. De igual forma, eligen los catálogos que sean fáciles de vender vía precio, calidad e innovación en la oferta, como lo afirma la participante 9: "en lo primero que yo me fijo es en las promociones que hayan venido, y también que hayan subido los productos que más vendo" (Mamá Entusiasta, entrevista personal, 54 años, estrato 2).

De las participantes también se entiende que para mantener la motivación en la venta por catálogo se deben tener en cuenta dos elementos. El primero es conocer que existen factores críticos dentro del negocio para ejecutar la labor de venta con eficiencia: mostrar el catálogo la mayor cantidad de veces posible, entablar una relación de cercanía con quienes compran el producto, insistir en la venta, tener buena actitud y gestionar el cobro. La participante 2 afirma que es importante tener buen carisma con la gente, explicarles a los clientes cómo son los productos, cómo se manejan y qué beneficios tienen, y añade: “convencer a la gente es clave" (Mamá Entusiasta, entrevista personal, 50 años, estrato 3).

El segundo elemento para mantener la motivación es que las participantes en su mayoría identifican que, adicional a estos pasos clave, se deben realizar otras tareas adicionales: interiorizar las ofertas y premios de campaña, ofrecer la exclusividad e innovación de los productos y entregar el producto a tiempo. La participante 8 menciona: "yo me pongo a mirar todo detalladamente y también cuánto es la meta para un premio que me guste" (Joven Independiente, entrevista personal, 21 años, estrato 3). Ser consciente de estos dos elementos permite mantener la atención en cada nueva campaña de ventas. 
En definitiva, los motivadores pasan a ser una cuestión interrelacionada de intereses personales, la percepción que tienen del negocio de venta por catálogo que se presenta como una oportunidad y cómo el ambiente familiar influye en sus decisiones.

\subsection{Momentos y factores que influyen en la fidelización de las vendedoras de venta directa}

Se encontraron ciertos momentos y factores que marcan las motivaciones y las experiencias memorables de las personas al vender por catálogo. A continuación, se explica cómo influyen positiva o negativamente en la fidelización de las vendedoras.

\subsubsection{Momentos y factores positivos}

Fue común escuchar en las Jóvenes Independientes y Mamás Entusiastas que uno de los momentos más llamativos es participar en las "reuniones de conferencia" organizadas por las empresas gestoras, pues las hace sentir parte de una comunidad y las entretiene; en estas reuniones expresan lo que opinan y comparten con otras personas. Al respecto, la participante 1 dice que "(en las reuniones de conferencia) Le explican a uno cómo vender. Son reuniones de lanzamiento de campaña y yo voy a casi todas; no me las pierdo porque es muy bueno estar enterado" (Mamá Entusiasta, entrevista personal, 45 años, estrato 3).

Las participantes mencionaron los sentimientos que tuvieron en momentos positivos con una empresa de venta por catálogo, y la mayoría experimentó alegría y confianza, asociadas al momento de llegada del pedido y a los productos de buena calidad. Ya sea que en sus cajas de pedidos haya premios o no, se genera una expectativa con los productos, el catálogo nuevo y las posibles sorpresas de la campaña, por lo que es importante generar dicha ilusión o curiosidad con cada entrega. La participante 12 relató una experiencia memorable al ganar un obsequio:

Algo que me pasó muy bonito (fue que) en mayo me gané un televisor para el niño, lo luché y me lo gané. En la campaña estaba segura que no, y en la reunión (de conferencia) me habían dicho que tenía que hacer (afiliar) tres nuevas (personas) para poder cumplir. Yo tenía un grupo pequeño, inscribí a cinco personas, pero solamente dos me 
dijeron que sí, las otras, no. ¡Y a última hora, una sí (se inscribió)! Y eso me ayudó a mí a ganar ¡no, qué alegría! (Joven Independiente, entrevista personal, 33 años, estrato 2)

Esta experiencia es un ejemplo del enfoque que una vendedora le puede dar a los premios, cuya motivación principal es la alegría de su hijo. Se sugiere que las empresas gestoras de venta por catálogo deberían garantizar una planeación en la oferta de valor asociada a productos, premios y detalles que susciten sentimientos de alegría y sorpresa en los familiares de sus vendedoras. La planificación de las cajas debe incorporar elementos útiles y afines a los ciclos de vida de las personas involucradas. Se sugiere una inversión en pequeños detalles que no solo estén amarrados a montos de ventas, sino que involucren emoción, cercanía y generen expectativa con el pedido.

Para las Jóvenes Independientes tener la posibilidad de comprar desde el hogar, ser autoconsumidoras del catálogo y ver la satisfacción de sus clientes, son elementos que influyen de manera positiva en la continuidad de la venta; mientras que las Mamás Entusiastas benefician la interacción con otros como un aspecto deseable porque buscan socializar. Es coherente con lo mencionado en sus motivaciones, pues las jóvenes trabajan de manera formal y operan su negocio en momentos libres como complemento a sus ingresos y entre más sea la comodidad y confiabilidad de un negocio, ellas estarían dispuestas a probarlo. Entre tanto, las Mamás Entusiastas pueden realizar una mayor gestión de venta y entablar relaciones de cercanía con otras personas, y ello deja en evidencia que la necesidad de afiliación con otros es un estímulo positivo en la fidelización.

En resumen, son desencadenantes de experiencias memorables las respuestas que las vendedoras tienen frente a los planes de premios, los detalles en su pedido, la generación de redes de contactos, la practicidad de la operación en conjunto con las herramientas tecnológicas y la cercanía en la comunicación. Las participantes sugieren que estos puntos suscitan la fidelización con los negocios de venta por catálogo.

\subsubsection{Momentos y factores negativos}

Las Jóvenes Independientes consideran que los cambios y las devoluciones son los aspectos más tediosos, consecuentes con la percepción que tienen del tiempo y de no querer perderlo en reprocesos. Por su lado, las Mamás Entusiastas mencionan los agotados en los 
pedidos y el incumplimiento en la entrega como puntos decisivos que influyen de forma negativa en su negocio. La participante 4 menciona: "que yo pida algo y no me lo manden, me ofusca, me dan rabia los agotados" (Mamá Entusiasta, entrevista personal, 61 años, estrato 3). Esta madre deja en claro que el cumplimiento de la palabra es garantía en la construcción de cercanía con los clientes. Dichos factores motivan la pérdida de interés en las condiciones de un catálogo, cuando los malos procesos administrativos interfieren en su proceso personal de ventas.

Hubo una similitud notable en ambos grupos de participantes al escuchar la decepción e incomodidad que sienten cuando un cliente tiene problemas para pagar. Son usuales los casos en los que un pedido no se paga a tiempo, y sin querer, una vendedora podría terminar su relación con una empresa gestora. A esto se le suman los procesos de cartera que vuelven más penoso el momento de cobro y la posibilidad de abrir un historial crediticio negativo de una vendedora. El aspecto anterior se convierte en un potencial momento de deserción, pues con frecuencia se presentan roces entre el comprador y el vendedor. Por lo tanto, una empresa sería más valorada si logra convertir este momento en algo menos angustioso y si atenúa el impacto de no recibir el dinero de un producto. La participante 11 expresa que:

\footnotetext{
Estar encima de la gente es como maluco. (¿Por qué?) Porque se supone que usted le ofrece (a alguien), y es una ayuda para usted y que ella (el cliente) sabe que con eso le está ayudando, y sabe que tiene unas fechas de pago, (hay personas que) no les gusta que les cobren, ¿entonces para qué no pagan? (Joven Independiente, entrevista personal, 33 años, estrato 2)
}

En suma, para generar fidelización en el negocio de venta directa se debe tener en cuenta que las Jóvenes Independientes prefieren empresas con planes de premios acordes al esfuerzo realizado y si se presentan cambios y devoluciones de pedidos que puedan ser gestionados de la manera más fácil posible, se sugiere que estos trámites se realicen desde sus casas, sin tener que desplazarse a otro lugar. Las Mamás Entusiastas quieren empresas con un relacionamiento constante con todas sus vendedoras y con una eficiencia operativa impecable (entregas a tiempo y sin agotados). La participante 1 menciona al respecto que le gustaría "más acompañamiento: que le estén explicando a uno los beneficios pues uno posiblemente se los está perdiendo por desconocimiento" (Mamá Entusiasta, entrevista personal, 45 años, estrato 3). Estos elementos influyen de manera positiva en la fidelización, porque 
las motiva con procesos sencillos, con obsequios que ellas prefieren, les ahorra tiempo en sus agendas, las hace partícipes de las actividades y se sienten parte de una comunidad que las tiene en cuenta de forma individual.

\section{Discusión}

Algunos resultados de esta investigación están de acuerdo con hallazgos de investigaciones ya realizadas en asuntos relacionados con las motivaciones de las mujeres para vender por catálogo, el cambio del rol de la mujer en el hogar, la facilidad para el manejo del tiempo que les permite la actividad de venta por catálogo, los sentimientos que despiertan en las mujeres el recibir un buen producto en la puerta de sus casas y el impacto positivo que puede brindar el envío de una caja que no solo contenga los productos, sino también detalles pensados para ellas. En general, no se encuentran resultados que refuten estudios anteriores; sin embargo, lo encontrado en la interpretación de los datos aporta a un mayor entendimiento de la realidad de estas vendedoras, sus motivaciones y factores que influyen en su fidelización. A continuación, se discuten estos hallazgos con las investigaciones previas identificadas.

Las motivaciones de las mujeres para vender por catálogo según sean Jóvenes Independientes (20-45 años) o Mamás Entusiastas (45 años en adelante) son acordes a las preferencias de las madres colombianas (Dinero, 2016): las madres millennials entre 18 y 34 años valoran el tiempo para ellas y la oportunidad de descansar (elementos que pueden traducirse en la búsqueda de paseos, tratamientos de belleza o spas) en medio de una realidad común en la que se evidencia el poco tiempo libre. Por otro lado, las madres mayores a 35 años benefician los espacios con sus familias (y, por ende, buscan momentos como cenas o parques para compartir). También los dos grupos quieren algo en común: experiencias (Dinero, 2016).

Otro aspecto para destacar es el aumento significativo de los últimos años en la contribución a la actividad económica del hogar: ahora las mujeres están cambiando su rol de ama de casa por jefe de hogar, toman más decisiones y buscan productos que les faciliten 
la vida, que optimicen tiempos y esfuerzos y que satisfagan mayor cantidad de necesidades (Nielsen, 2014b). Esto coincide con el deseo de ambos perfiles de vendedoras en aportar económicamente al hogar por medio de la venta directa.

Un claro hallazgo en la investigación fue que mientras más sencillos sean los procesos de la venta por catálogo, gracias a las nuevas tecnologías, las vendedoras encontrarán un motivante para participar en dichos negocios sin descuidar sus hogares. Lo anterior es coherente con lo que afirma Acovedi (2015), al destacar que las personas que venden por catálogo encuentran en el negocio no solo un crecimiento personal, al mejorar aptitudes de comunicación o cambios positivos en sus rutinas, sino que reafirman el valor de una actividad muy flexible que les permite manejar el tiempo a su antojo. Acovedi (2019b) agrega que las nuevas tecnologías le han aportado a este negocio, el cual ha sabido aprovechar los avances del sector tecnológico y el fomento al emprendimiento. Este negocio se caracteriza por la innovación continua en las formas de difusión, en la creación de contenidos y crecimiento de comunidades, elementos que las vendedoras perciben con facilidad.

Los sentimientos de alegría y confianza que sienten las vendedoras en el momento de recibir los pedidos y que estos hayan llegado con buena calidad son elementos coherentes con lo expresado por Segura y Garriga (2008):

\footnotetext{
Las experiencias no suceden porque sí, hay que planificarlas, hay que ser creativo, sorprender, intrigar y en ocasiones provocar. También hay que incorporar — siempre que se pueda_ en los modelos tradicionales la experiencia sensorial, intuitiva. Hay que pensar en la situación de consumo. Ya hemos visto que el producto puede ser el mismo y lo único que cambia es la experiencia personal que se da en el consumo. (p. 270)
}

De acuerdo con los autores, las vendedoras identifican ciertos momentos y experiencias memorables que no "suceden porque sí", sino que deben ser planificados por las empresas gestoras y renovadas periódicamente según la realidad de las vendedoras para no perder su interés.

Respecto al hallazgo de la planificación de las cajas, en el cual se afirma que es necesaria una inversión en detalles que generen emoción y alegría, se identifica que este hallazgo está de acuerdo con lo afirmado por González y Poey (2011), quienes aseguran que el 
objetivo es generar una vivencia, lo cual no implica usar grandes cantidades de recursos, pero donde lo importante es conducir al vendedor a un estado en el que su reacción frente al producto-servicio acarree actos de compra repetitivos. Dicha postura es complementada por Huang et al. (2018), al afirmar que no es una sorpresa que las vendedoras benefician las recompensas monetarias, pero en el fondo ellas quieren sentirse especiales y reconocidas.

En cuanto a los momentos y factores positivos identificados, se aclara que estos pueden llevar a experiencias memorables en las vendedoras, pero en sí mismos no generan fidelidad, aunque sí la facilitan. En realidad, y como bien lo explican Gentile et al. (2007), las experiencias memorables no deben ser lo principal en un servicio, sino el permitir que la mayoría de momentos de la experiencia entre la compañía y un vendedor se lleven a cabo de una manera excelente, idealmente más allá de las expectativas del vendedor y logrando experiencias de cocreación con la compañía. Es decir, no solo las experiencias memorables generan fidelidad, sino un grupo de factores que de manera conjunta incentivan a la vendedora a seguir ofreciendo los productos del catálogo, subir sus niveles de ventas y continuar la relación con la empresa gestora. Sin embargo, se aclara que estas experiencias memorables entre las vendedoras y las empresas gestoras sí ayudan a aumentar la motivación de las vendedoras y, por tanto, su fidelización; además, en algunos casos, permiten que una vendedora desmotivada permanezca y persevere en su tarea de ventas.

En cuanto a los momentos y factores negativos, los eventos que obstaculizan la gestión de ventas derivan generalmente en vendedoras aburridas y detractoras del modelo de negocio de venta directa. Es evidente que las consecuencias de tal insatisfacción son negativas, no solo porque las vendedoras abandonan la relación con la empresa, sino porque experimentan desconfianza hacia ella o hablan negativamente (Varela et al., 2009). De acuerdo con Smith y Bolton (2002), la respuesta de la empresa a las situaciones de inconformidad es un importante momento que determinará los comportamientos de las vendedoras en un futuro.

Dichos momentos y factores positivos y negativos pueden relacionarse con los principios desarrollados por Devine y Gilson (2010), para llevar a cabo una estrategia de experiencias memorable. Las empresas podrían anticiparse a describir mejor ciertos procesos para mejorar la experiencia de las vendedoras: 1) explicar desde el comienzo las incomodidades frente al cobro de productos y ofrecer diferentes medios y plazos de pago, 
entrenamiento en cobro, créditos especiales para clientes importantes o consejos para la elección de clientes adecuados; 2) mitigar el fuerte impacto de los agotados, revisando el orden en la toma de pedidos y garantizando diversos canales a los que puedan ir las personas para realizar una devolución; 3) planificar finales de alto impacto, asegurando elementos sorpresa con cada llegada del pedido; 4) generar hábitos en las reuniones de lanzamiento de campaña que deben ser un ritual cada 21 días (o de acuerdo con la periodicidad de la empresa gestora), donde se faciliten relaciones con otras personas, $y$ 5) posibilitar momentos en los que se les informe y pregunte respecto a diferentes estrategias comerciales o premios que desean ver para campañas venideras y, de esta manera, los clientes se sentirán escuchados e incluidos.

Estas estrategias coinciden con las ideas propuestas por Beckers et al. (2014), al afirmar que las organizaciones deben mantener un diálogo constante y en doble vía con las personas, porque los medios de comunicación y la revolución digital les han dado herramientas efectivas a los consumidores para comprometerse con una empresa como coproductores o destructores de valor.

\section{Conclusiones}

Para analizar cómo las experiencias memorables de las vendedoras por catálogo propician su fidelización, los resultados de este estudio perfilaron a las vendedoras participantes en dos tipos: Jóvenes Independientes y Mamás Entusiastas. Mientras las participantes más jóvenes, las Jóvenes Independientes, privilegian la búsqueda de independencia, sueños personales y realización profesional; las participantes de mayor edad, las Mamás Entusiastas, son motivadas por la tranquilidad de sus familias y la soledad. Ambos grupos perciben a los catálogos son una herramienta para cumplir el deseo de ver a sus familias en paz y con salud; les angustia no tener con qué pagar las cuentas de la casa o estar en un momento de necesidad. Sobre esta situación, ven indispensable el trabajo de dos personas para sostener sus hogares, y cuidan mucho el dinero que ganan tratando de optimizarlo al máximo. 
Al respecto del negocio de la venta directa, se encuentra que las vendedoras participantes son autoconsumidoras de los múltiples catálogos que ofrecen y son, además, muy sensibles a la variable precio. Las participantes de más edad venden catálogos, porque es una oportunidad de negocio en un mercado laboral donde el trabajo formal es escaso y las jóvenes encuentran en ellos un complemento a sus ingresos actuales, que pueden gestionar en los momentos libres de sus empleos. Ambos grupos encuentran en estas compañías una opción cómoda para generar ingresos. Adicionalmente, señalan la importancia de tener en cuenta las ofertas y premios de cada campaña, la exclusividad e innovación de los productos y entregar el producto a tiempo. Las participantes sugieren desear una mayor cercanía de la empresa para mantenerlas informadas, premios fáciles de adquirir y acordes al esfuerzo realizado en ventas, eficiencia operativa para garantizar que no hayan agotados, devoluciones en casa, entrega oportuna de pedidos, innovación y diversidad en los productos ofrecidos. Todo esto se podría lograr con un mejor uso de la tecnología en los procesos de las empresas gestoras.

Las implicaciones prácticas de los hallazgos buscan generar una reflexión acerca de los desencadenantes de experiencias memorables y los elementos motivacionales de las vendedoras, con el objetivo de incorporarlos en las estrategias de fidelización del negocio de venta directa en Antioquia, particularmente en el Área Metropolitana del Valle de Aburrá. En este documento se entregan insights para generar una comunicación más cercana y efectiva hacia las vendedoras y aclara aspectos de la vida de estas mujeres que pueden ser mejorados o solucionados a través de estrategias comerciales.

Acorde a los hallazgos de las motivaciones de las participantes, las empresas gestoras podrían fortalecer el sentido de pertenencia de la comunidad de vendedoras a través de estrategias de cooperación; entonces, conectar a las personas entre sí desde el momento en que ingresan al negocio debe ser uno de los pilares clave en la fidelización del negocio. En este sentido, el fortalecimiento de las herramientas tecnológicas es fundamental para compartir con los demás, y garantizar el acceso a las diferentes propuestas del negocio y a los catálogos en línea.

La principal implicación teórica del estudio, según lo encontrado en los perfiles de las vendedoras, es conectar las experiencias memorables con aquello que les da tranquilidad a ellas. Es decir, aunque las experiencias memorables generalmente tienen un alto 
contenido emocional, lo que es más importante para las vendedoras es que estas llevan, en general, tranquilidad a sus hogares, punto no mencionado hasta ahora en la literatura consultada. Llevar a las vendedoras a vivir una experiencia memorable puede ser un motivo de fidelización, pero lograr que dicha fidelización sea la consecuencia del aporte en la estabilidad en sus vidas es obtener una ventaja adicional para ser competitivos. Las empresas gestoras del negocio de venta por catálogo deben ofrecer experiencias con un trasfondo ligado a sus motivaciones primarias, que lleven a las personas a cuidar de sus familias, lograr su independencia o superarse personal y profesionalmente.

Por el tipo de estudio realizado, los hallazgos no deben ser generalizados para el resto de Colombia, debido a las diferencias regionales, que implicarían un acercamiento diferente con las vendedoras. Futuros estudios podrían considerar la relación de la satisfacción, el valor percibido, la confianza, la imagen corporativa, la calidad del servicio, los programas de fidelización y los trade offs en la fidelización de los negocios de venta por catálogo en el Área Metropolitana del Valle de Aburrá. También la relación de la venta por catálogo con negocios colaborativos, el impacto social que la baja rotación del negocio puede generar e investigaciones de los perfiles de las vendedoras en otras zonas del país. Por último, basados en Zomerdijk y Voss (2010), es posible utilizar los customer journeys (mapas de viaje aplicados al vendedor) para proponer el rediseño de una experiencia de servicio con mayores puntos de contacto y experiencias positivas entre el vendedor y la empresa gestora.

\section{Referencias}

Aaker, D. (1991). Manejando el valor de marca: capitalizar el valor del nombre de marca. Free Press.

Alet, J. (2007). Campañas efectivas con sus clientes: Marketing directo e interactivo. Esic.

Amnistía Internacional. (2018). Informe 2017/18 Amnistía Internacional, la situación de los derechos humanos en el mundo. https://www.amnesty.org/download/Documents/ POL1067002018SPANISH.PDF

Asociación Colombiana de Venta Directa (Acovedi). (2015). Resumen ejecutivo: impacto social y económico de la venta directa en Colombia 2015. https://acovedi.org.co/wp-content/ uploads/2018/02/Resumen_Social_y_Economico_Venta_Directa_2015-1.pdf 
Asociación Colombiana de Venta Directa (Acovedi). (2019a). Acovedi. https://acovedi.org.co/ venta-directa/

Asociación Colombiana de Venta Directa (Acovedi). (2019b). Colombia: venta directa mueve $\$ 4,8$ billones al año. America Retail. https://www.america-retail.com/colombia/colombia-venta-directa-mueve-48-billones-al-ano/

Bates, C. (2016, 25 de marzo). ¿Es Avon un negocio atractivo todavía? $B B C$. http://www.bbc. com/mundo/noticias/2016/03/160317_economia_avon_mujeres_finde_ilm

Beckers, S., Risselada, H., \& Verhoef, P. (2014). Customer engagement: A new frontier in customer value management. En R. T. Rust \& H. H. Ming (Eds.), Handbook of service research. Edward Elgar.

Bowen, J., \& Shoemaker, S. (1998). Loyalty: A strategic commitment. Cornell Hotel and Restaurant Administration Quarterly, 39(1), 12-25.

Cadavid, H. (2004). Marketing de emociones: la forma para lograr la fidelidad de los clientes. Semestre Económico, 7(13), 204-211.

Chu, M., \& Segre, J. (2010). A note on direct selling in developing economies (Case No. 9-310068). Harvard Business School Publishing.

Corbin, J., \& Strauss, A. (2002). Bases de la investigación cualitativa, técnicas y procedimientos para desarrollar la teoría fundamentada. Editorial Universidad de Antioquia.

Crittenden, V. L., Crittenden, W. F., \& Ajjan, H. (2018). Direct selling in South Africa: Empowering women entrepreneurs. Association for Small Business and Entrepreneurship.

Devine, J., \& Gilson, K. (2010, 1 de febrero). Using behavioral science to improve the customer experience. McKinsey Quarterly. https://www.mckinsey.com/business-functions/ operations/our-insights/using-behavioral-science-to-improve-the-customer-experience

Dinero. (2016, 5 de agosto). ¿Cuáles son los hábitos de las mamás de ahora? https://www. dinero.com/pais/articulo/segun-un-estudio-de-ibope-media-estos-son-los-habitos-de-lasmamas-colombianas/223378

Gentile, C., Spiller, N. and Noci, G. (2007). How to sustain the customer experience: an overview of experience components that co-create value with the customer. European Management Journal, 25(5), 395-410.

Gobernación de Antioquia. (2017). Estratificación socioeconómica de viviendas. Departamento Administrativo de Planeación-Dirección Sistema de Indicadores. http://www.antioquiadatos.gov.co/ 
Gómez, C. (2015, 27 de octubre). La venta directa crece 10 \% y mueve negocios por \$6 billones. Portafolio. http://www.portafolio.co/negocios/empresas/venta-directa-crece-10-mueve-negocios-billones-37156

González, M. A. (2016). International expansion opportunities for multi-level marketing via personal networks: An ethnographic study from Colombia. International Journal of Business and Society, 17(1), 28-46.

González, M., \& Poey, R. (2011). El marketing de experiencia y la lealtad de los clientes. Retos Turísticos, 10(3), 16-21.

Guber, R. (2001). La etnografía: Método, campo y reflexibidad. Norma.

Huang, J., Rothschild, P., \& Wilkie, J. (2018, 2 de julio). Why customer experience is key for loyalty programs. MIT Sloan Management Review. https://sloanreview.mit.edu/article/ why-customer-experience-is-key-for-loyalty-programs/

Hume, M., Sullivan Mort, G., Liesch, P. W., \& Winzar, H. (2006). Understanding service experience in non-profit performing arts: Implications for operations and service management. Journal of Operations Management, 24(4), 304-324.

Homburg, C., Koschate, N., \& Hoyer, W. (2005). Do satisfied customers really pay more? A study of the relationship between customer satisfaction and willingness to pay. Journal of Marketing, 69(2), 84-96.

Jiménez, J. P. (2015). Desigualdad, concentración del ingreso y tributación sobre las altas rentas en América Latina. Comisión Económica para América Latina y el Caribe. https:// repositorio.cepal.org/bitstream/handle/11362/39662/S1420855_es.pdf?sequence=1

Johnson, M. D., Herrmann, A., \& Huber, F. (2006). The evolution of loyalty intentions. Journal of Marketing, $70(2), 122-132$.

Jones, M. (s.f.). The intersection of business, growth and technology. Cox Blue. https://www. coxblue.com/the-art-of-customer-loyalty-in-the-age-of-consumer-experience-and-engagement/

Kotler, P., \& Keller, K. (2006). Dirección de marketing (12. ${ }^{\mathrm{a}}$ ed.). Pearson Education.

Kotler, P., \& Keller, K. (2012). Dirección de marketing. Prentice-Hall.

Lemon, K., \& Verhoef, P. (2017). Understanding customer experience throughout the customer journey. Journal of Marketing, 80(6), 69-96.

Ley 142, artículo 102. (1994). Por la cual se establece el régimen de los servicios públicos domiciliarios y se dictan otras disposiciones. http://www.funcionpublica.gov.co/eva/gestornormativo/norma.php?i=2752 
Mascarenhas, O. A., Kesavan, R., \& Bernacchi, M. (2006). Lasting customer loyalty: A total customer experience approach. Journal of Consumer Marketing, 23(7), 397-405.

Nielsen. (2014a). Venta Directa, un fenómeno en crecimiento en los hogares colombianos. http://www.nielsen.com/co/es/insights/news/2014/venta-directa-colombia.html

Nielsen. (2014b). ¿Quién es y cómo se comporta el shopper colombiano? https://www.nielsen. com/co/es/insights/news/2014/shopper-colombiano.html

Ongallo, C. (2007). El libro de la venta directa: el sistema que ba transformado la vida de millones de personas. Díaz de Santos.

Pine II, B. (2011, 25 de abril). Memorable events are the most valuable experiences. Harvard Business Review. https://hbr.org/2011/04/memorable-events-are-the-most

Pine II, B., \& H. Gilmore, J. (2014). A leader's guide to innovation in the experience economy. Strategy \& Leadership, 42(1), 24-29.

Portafolio. (2019, 16 de abril). Ventas directas crecieron alrededor del 5\% en 2018. https:// www.portafolio.co/economia/ventas-directas-crecieron-alrededor-del-5-en-2018-528653

Posada, Á. M., Dávila, J., \& Castro, V. (2008). Perfil psicográfico de los compradores de venta directa por catálogo en Manizales [tesis de grado]. Universidad de Manizales, Colombia. https://es.scribd.com/document/322795846/Angela-Maria-Posada-Rodriguez-2008

Santoro, F. (2019). De Medellín para Latinoamérica. La República. https://www.larepublica. co/analisis/flavia-santoro-2807402/de-medellin-para-latinoamerica-2857993

Segura, C., \& Garriga, F. (2008). Marketing experiencial: el marketing de los sentimientos y sus efectos sobre la mejora en la comunicación. En II International Conference on Industrial Engineering and Industrial Management (pp. 267-272).

Semana (2019, 5 de abril). Desempleo y migración disparan niveles de desigualdad. https:// www.semana.com/nacion/articulo/desempleo-y-migracion-venezolana-disparan-desigualdad-y-pobreza-en-colombia/612458

Smith, A. K., \& Bolton, R. N. (2002). The Effect of customers' emotional responses to service failures on their recovery effort evaluations and satisfaction judgments. Journal of the Academy of Marketing Science, 30(1), 5-23.

Spiggle, S. (1994). Analysis and interpretation of qualitative data in consumer research. Journal of Consumer Research, 21(3), 491-503.

Stan, V., Caemmerer, B., \& Cattan-Jallet, R. (2013). Customer loyalty development: The role of switching costs. Journal of Applied Business Research, 29(5), 1541-1554.

Tung, V. W. S., \& Ritchie, J. R. B. (2011). Exploring the essence of memorable tourism experiences. Annals of Tourism Research, 38(4), 1367-1386. 
Varela, C., Vázquez, R., \& Iglesias, V. (2009). Comportamiento de abandono de la relación de un cliente con la empresa en un contexto de fallo y recuperación del servicio. Cuadernos de Economía y Dirección de la Empresa, 40, 143-170.

World Federation of Direct Selling Associations (WFDSA). (2018). Estadísticas globales (20152018). https://wfdsa.org/global-statistics/?lang=es

Zomerdijk, L. G., \& Voss, C. A. (2010). Service design for experience-centric services. Journal of Service Research, 13(1), 67-82. 